\title{
Reconstructing the New Concept of Football Education in Colleges
}

\author{
Shuaicheng Luo and Xiaomin Zhou
}

\author{
NanChang Institute of Science \& Technology, Nanchang,330108
}

Keywords: Colleges; Football culture; Construction; Training concept

\begin{abstract}
Football sport, as a sport event with a long history, has been popular with the masses of Chinese by virtue of its passion and teamwork characteristics. Especially during the football sports development and football training practice, it has obtained the experience of football construction and detailed method, compacting sport culture which conforms to the national conditions of our country and carries the functions of the popularization and development of sport culture, it is of great historical and practical significance to promote the sustainable development of China's football industry. However, China's football career is stepping into a "downhill" stage, no matter that in the management or competition they are not satisfactory. This is bound to cause the country to attach great importance to the development of football, seeing from the football reform program announced this year and some of the relevant policies ago, we can obviously feel that in the current or future period, achievement of football development will focus on school sports.
\end{abstract}

\section{Introduction}

With the development of domestic and international sports training and sports competition practice, people's views on the technical problems of the subject-oriented project have risen to the level of "training idea", and the original training concept having been re-examined in the spirit of advancing with the times has become the requirements of the times. The integrity, confrontation, variability, hardship of football are more requiring the training concept to get continuous development with the development of practice.

With the development of football, to change the training concept to adapt to the essential characteristics and trends of the sports. Advanced training concept is a strong guarantee to promote the development of sports training, an important prerequisite to achieve the goal, fully embodying the essence of sports training and methods. China's football wandering status has a close relationship with the lack of correct training concept. Sports industry leaders and managers have repeatedly pointed out that the backwardness of the training concept is the main cause of backward China's football. Therefore, to clarify the connotation of the concept of training concept, to examine the formation and development of the concept of football training and to construct advanced training concept is of great theoretical significance to the development of football in China.

\section{Definition of Football Training Concept}

Football concept, refers to the football ideas and concept. It is the deepest level of football culture, generated and developed on the basis of football practice of the people, it is one kind of view and understanding from the macro to micro situation in the development trend to the basic movement law. Sport concept includes the concept of player selection, football training concept, football game concept, football management, it determines all the activities people being engaged in football. Sport concept was initially budded in the sports career of football players, accompanied by the conversion of the roles of athletes to coaches and the deepening understanding on the law of football, the concept of football has gradually formed and further enriched, developed and innovated. Self-football career and coaching experience of coach is the key to the formation of its football concept. At the same time, their own humanities quality, football professional theory and related disciplines knowledge, team management experience and the thinking on development trend of modern football also are the key links for the formation of football concept.

Sport training concept is a branch of the concept of football, it is included in the football concept. The concept of football training is the objective understanding on the definition of football, 
characteristics, trends, laws, roles and values based on the football teaching and training of the football coach, are the fundamental judgments and views on football training made by the coach, is the idea and concept to guide football training. It is the guidance of a coach engaged in combination of football training theory and practice, but also the combination of theory and practice of the media. Therefore, from the point of practice, the correctness and wrong of the training concept is related to the direction and achievements of football development. In theory, the concept of football training is judgement and view of coach on the practical training, has a pointing role in the football training practice.

In the history of the development of competitive sports, countless cases have repeatedly proved such a proposition: advanced training concept promote the continuous improvement of competitive strength, while backward training concept will inevitably lead to invalid, and even destructive training, resulting in the slowness of competitive strength improvement. To establish the correct and scientific concept of sports training is the basic premise and fundamental guarantee to improve the level of football in China.

\section{Discussion on the basic Characteristics of Modern Football}

Intense Time and Space Confrontation is an Important Feature of Modern Football Game. Football is the ball and the gate that the two teams move round the space in a certain period of time, mainly using the feet to control the ball, in a certain range, to launch a fierce offensive and defensive confrontation, use the scores to determine the outcome of a sport. So in the course of the game, the awareness of time and space concept must be strong, and use of various forms, methods and means by wisdom, to fight for time and space advantage, treating controlling the ball and the goal score as the purpose, and then to win the game, to meet the requirements that the game become more opposability.

Instant Attack and Defensive Conversion is a Prominent feature of Modern Football game. Fast offensive and defensive conversion is an important feature of modern football game, is the embodiment of the coach tactical arrangement of ideas and details, but also is one of signs that the team has a high level of athletic ability with well-training. According to the rules of the football game, according to the number of points to determine who win or lose, while the game has set the time, after the attack they will fight, offensive and defense continue to convert, instant conversion is the key to take the initiative and control opponents. Modern football game, offensive and defensive changes in the impermanence, so that the game has always been maintained at a fast high rhythm, smooth game, giving people a suspense, which is the charm of football games.

Individual and Collective Integration is the basis of Winning of the Modern Football Game . Football is a collective sport that belongs to the dominant class of skills. It consists of 11 people for every team, now that it is called the team, it is necessary to treat team strength as the core, the cooperation with each other in the overall team is the basis for winning. Without overall collaboration, the team's cohesion and combat effectiveness will not be strong; Without overall collaboration, the outstanding personal technology will only be single in the game, it will not be useful to improve the overall technical and tactical and performance too much. The integrality emphasis on each team member must do close and work together, only the individual's technical and tactical ability are fully integrated into the whole team, the overall can provide a strong protection each team member, but also create more and better opportunities for personal technology, integrity is not to ignore the individual function, but focusing on the refraction of the overall function individual on the basis of playing free.

\section{The Key Points and Methods of Constructing the Concept of Football Training in China}

The construction of training ideas must pay attention to the cultivation of education concept of athlete humanistic quality. Humanistic quality refers to the relatively stable quality of people through the study of humanistic knowledge, the understanding of humanistic thought and the humanistic spirit, and manifests itself as behavioral tendencies, moral character, cultural 
accomplishment and aesthetic taste. It is also the all-round development requirements for human being. In the football training in China, neglecting the cultivation of humanistic quality of athletes results in athletes seeming more reckless and lack of wisdom in the fierce competition.

The construction of training ideas must highlight the essential characteristics of the sports and the law. Football is a sport that it is very intense against the body. The concept of football training should be based on the theoretical knowledge of football training, the scientific knowledge of philosophical thinking and the development trend of world football, and put forward the advanced football training concept based on the actual situation of our country.

The construction of training ideas must emphasize the scientific concept of training process. The process of improving the level of sports training is a process of deepening the understanding of project and project rules, which is the process of deepening the scientific training of project sports. Sport practitioners in the world are making full use of modern high-tech means to create the latest and most effective training methods to tap the potential of human movement, these scientific and technological practice activities enhance the degree of scientific training of sports training.

To strengthen multilateral exchange and learning with the world football strong team, to prompt the development by reference, and make innovation in the development, and strive to build China's football training concept to really adapt to the development trend of the world football. The football authorities as the leader to organize experts, scholars and high-level coaches to do a deeper level of research on the concept of football training, so that it can embody advanced nature and forward-looking of China's football training concept.

\section{Summary}

At present, the concept of football training in China is still having a gap with the development of world football. The lack of the concept of sport training in our country has affected the development of Chinese football technology to a certain extent. China's football training concept has not yet broken through the inherent ideas, compared with the European and American football power there is a considerable gap. The concept of football training is a general term for the study of football philosophy and ideas in the course of long-term football practice and theoretical learning, which combines the essence of sports training and the development trend of modern football. The construction of the concept of football training in our country should be: must pay attention to the humanistic quality of athlete culture education concept; must highlight the essential characteristics of the sport and the law; must emphasize the sports training process of scientific view.

\section{References}

[1] Himel M T. Big Game Cats and Defining Football's Value: College Football's Popularity, Controversies, and Expansion [J]. Dissertations \& Theses - Gradworks, 2015.

[2] OddsShark. College football Week 9 odds: Betting odds for most notable matchups [J]. Sports Illustrated Com, 2015.

[3] Heredeen F, Fellers R B. Nutrition Knowledge of College Football Linemen: Implications for Nutrition Education [J]. Journal of the American Dietetic Association, 1999, 99(9):A38.

[4] Jing L, Stephansson O. MP3 Songs of Higher Learning LLC-Grammar "Rock"[J]. Journal of Panzhihua University, 2014.

[5] Lowery J W. Selling. College: a longitudinal study of American college football bowl game public service announcements [J]. Journal of Marketing for Higher Education, 2014, 24(1):75-98.

[6] Yuan J, School of P E, University H A. Reflections on the Role of Football in College PE Education [J]. Journal of Guangzhou Sport University, 2016.

[7] Shi G M. Situation analysis and innovation road of College football teaching [J]. Heilongjiang Science, 2016.

[8] Cao L C, Gao Q P, Dai G Q. Experimental Research on Collaborative Teaching Model in Colleges Football Education [J]. Journal of Harbin Institute of Physical Education, 2014, 9(2):166-173. 
[9] Lynall R C, Kerr Z Y, Parr M S, et al. Division I College Football Concussion Rates Are Higher at Higher Altitudes [J]. Journal of Orthopaedic \& Sports Physical Therapy, 2016:1.

[10] Terry N, Pjesky R, Kelley G. Determinants of college football graduation rates [J]. Journal of Economics \& Economic Education Research, 2014, 15(2):207-220. 